\title{
Co-drawing: Forms of Spatial Communication as Formats for Collective Dialogue
}

\author{
ANTJE STEINMULLER \\ California College of the Arts
}

\begin{abstract}
'Co-drawing' explores architectural drawings as co-authored, cooperative instruments to envision multivalent and collective public space. This situates the architect as the designer of forms of/for public communication, spatial frameworks and tools stimulating multi-stakeholder involvement to visualize, advocate, recapture, and design. In public space design today, collaborations with multiple constituent stakeholders promote evolved architectural protocols and production. For the architect as expert, masterplans and guidelines give way to architectural frameworks for collective action, evolving development strategies, and multivalent designs.
\end{abstract}

Examining the space for architectural expertise in this context, this paper analyzes multi-centered representations as descriptions of rich, dynamic urban spaces freed of singular control, continuing utopian endeavors or developing realistic and democratic visions of urban space. It describes recent production of 'co-drawings' as co-authored documentaries of public space or cooperative frameworks stimulating citizen expression. Expanding on disciplinary trajectories of drawing and their implications for architectural expertise, this paper proposes a methodology for 'co-drawings' as interactive, spatial frameworks: pertinent tools to articulate multivalent public space and empower collective imagination.

\section{INTRODUCTION}

This age of increasing privatization of urban development and commercialization of public space has brought about strategies of resistance, resulting in new ways of producing public space. Ranging from occupations of residual urban sites to spontaneous takeovers of vacant buildings for community use, such acts of insurgency ${ }^{1}$ have brought together critical architects, designers and citizen groups from an increasingly diverse public to jointly initiate processes that uncover latent potentials and leverage collective action towards public space formation. Within these processes, the engagement and collaboration of multiple stakeholders necessitates a need for new protocols and processes - described here as architectural frameworks that harness citizen input and support collective action. Critical of the masterplan as an architect's primary device for the production of urbanity, these new modes of public space production have brought about a shift from design of the 'object' (the public space itself) towards the design of the 'interface' ${ }^{2}$ (or site of engagement), within which the public is an equal expert $^{3}$ in a collaborative work process. This paper posits that drawing as a collaborative act can constitute a productive interface with a constituent public. Co-drawing, as argued herein, is

\author{
CHRISTOPHER FALLIERS \\ California College of the Arts
}

seen as a valuable tool for active envisioning and archiving of consensus and productive dissensus. It is explored as both site and document of multi-centered descriptions of rich, dynamic urban spaces freed of singular control, an act that can record both idealistic visions and realistic projections of a collectively produced urban space.

Co-drawing situates the architect as the designer of tools for public communication and dialogue, specifically leveraging architectural expertise towards generating spatial and social frameworks that stimulate citizen engagement. Architectural expertise, here, extends to the framing and moderation of dialogue (framework 1: structuring conversation), the development of a base drawing as an instrument of/for capturing and curating citizen input (framework 2: designing interfaces), as well as the definition of a method of participation in drawing (framework 3: shaping engagement). The first part of this paper positions such drawing frameworks in the context of other participatory drawing experiments in art and urban design, as well as in the history of multi-centered drawing narratives - highlighting methods of observation and collaboration, the flattening of hierarchies in multi-centered representation, and the recording of social constructions over time. The second part of the paper describes a case study co-drawing project conducted by the authors in collaboration with students from California College of the Arts, Raumlaborberlin, and citizens of Berlin, in which different frameworks for drawing collaboratively were put to the test in a public event.

\section{DRAWING AS COPRODUCTION}

The use of drawing as an interface supporting the co-production of public space transforms conventional attributes and relationships. Representations depicting the potential of a city situated within that same city construct simultaneities of representational and lived urban space. The city and its representation can co-exist, allowing actors changing a part of the city to situate themselves within that context. The co-existence of authors, stakeholder needs and visions, and multivalent representational space transforms the media, content, and format of a drawing. Questioning a drawing's internal narrative and in-time completion, while recording many voices, in-process dialogues, and synthesis of information, suggest a drawing constructed in time. This foregrounds questions of media and expertise, or how an architectural representation can be approachable and engaging to a more active audience. Historical and contemporary innovations in urban representations hope to support this hypothesis. 
Especially within multi-centered compositions, representations of a city have long been used as a basis for critical and/or utopian discussions, and/or to capture the dynamism of/within urban formation. Pieter Bruegel the Elder's The Tower of Babel [1563] represents both the aspirations and critique. The painting is based on the Christian Bible's value ascribed to society identifying itself through its cities, "Then they said, 'Come, let us build ourselves a city, and a tower with its top in the heavens, and let us make a name for ourselves; otherwise we shall be scattered abroad upon the face of the whole earth.'" (Genesis 11:4). In parallel, as historian Barbara A. Kaminska observes, the painting was "originally displayed in the suburban villa of Antwerp entrepreneur Niclaes Jonghelinck as an image that fostered learned dinner conversation (convivium) about the well-being of the city." ${ }^{5}$ The urban representation acts here as the stimulant for the convivium's contemplation of 16 th century urbanity.

These early representations can be simultaneously idealistic and critical. Art historian Hans Belting interprets Hieronymus Bosch's The Garden of Earthly Delights [c. 1480-1505] as both utopian and realistic. Its content reflects a "remarkably modern freedom...," "normally guided by compositional structure, here we become lost in an overfilled panorama whose motifs appear like a compendium but cannot be read like one..., revealing the illusory aspect of the way things look in reality. ${ }^{\prime 6}$ Bosch expands upon the prevailing triptych format both internally and eternally. Each panel holds multiple scenes and multiple painterly color effects, resulting in a multi-centered composition. He also positions the representation as an artifact in real space. An immersive triptych when open, within a fourth set of panels when closed, the only way to perceive the four narrative representations is to engage it spatially, either moving around it or opening the work.

On Bosch, architect Jimenez Lai posits that "no single center of gravity to dominate the discourse" offers potential for plural visions of constructed space - "an investment in anecdotes: the parts will be more than the sum" ${ }^{8}$ vs. a more singular disciplinary vision or argument. In Lai's own work, we see both the use of multi-centered compositions and the displacement of the $2 \mathrm{D}$ representation into immersive space. For "insideoutsidebetweenbeyond" [2014], Lai cites Bosch's influence, both as an examination of utopian and heterotopian space, and as a quasi-urban flattening of space and social relations. In his Beachside Lonelyhearts gallery installation, all ceiling, floor, and wall surfaces are a canvas for drawing. This immersive wallpaper effect compresses representational and actual space. Critic John McMorrough argues Lai's own multivalent work continues utopian dialogues addressing "questions of how architecture is represented - its social context, its possibility, and, finally, its continuing resonance - in pocket universes where possibility is unregulated."
Lai's representational flattening is spatial, in its equivalence between perceived interior and exterior, and disciplinary, through a collapse of architectural representation, thought bubbles, and everyday doodles. The latter brings the expertise of architectural drawing on par with the comic book. This flattening of hierarchies of composition, expertise, and hand depicts representations of the city with more 'approachable media', media with spatial legibility yet open to non-expert hands. These compositional and media tactics are important ingredients for co-production, as this media moves from limited expert authors addressing a narrow audience to the possibility of many heterogenous authors constructing a representation for their own communal goals. They contain the observational and design expertise of the discipline, but are more open to participation and direct engagement.

This harkens back to Archigram's use of media and mass communication. The front cover of Archigram Nine, Fruitiest yet FREE SEED OFFER [1970], depicts everyday life in mode of representation akin to comic-books and popular magazine illustrations. These recognizable everyday representations depict and heighten an awareness of personal and common space. The back cover of Archigram Nine adds a twist. It rerepresents only parts of the front cover, prompting the user to act on the drawing. This produces an incomplete, coloring book-type invitation for users to envision their own everyday life and space.

Archigram's sequential drawings for Instant City [1969] can be seen as an analogy for the architect's role in the co-production process. Archigram's series of drawings depicting the project sequence in six steps (Before IC: A Sleeping Town, Decent, Event, Highest Intensification, Infiltration, Network Takes Over). As the Instant City blimp constructs a new form of urbanism for a limited duration, it leaves a lasting impact for the citizenry, the seeds of a new self-reliance, and a network to foster external connections. As the co-production of public or common space necessitates negotiating where expertise and control have potentials and limits, co-drawing can take clues from this analogous approach. It posits that the early design acts as the input of architectural expertise through a temporary engagement/installation, acting as stimulus for community dialogue.

Contemporary practices examine co-produced urban representations. These focus on the space of everyday urbanism, solicit critiques and aspirations for citizens' own space, and design of formats for community engagement. As frameworks for dialogue, activation, interpretation by others, the attributes of approachability and participation as activation are key. As influenced Archigram's Dennis Crompton, Raumlaborberlin's Architecture Beyond Building, Stick on City (Venice Biennale) [2008] situated a co-drawing of an imagined, partially completed city with a gallery space. A workshoplike table prompted the public to add line drawing patches 


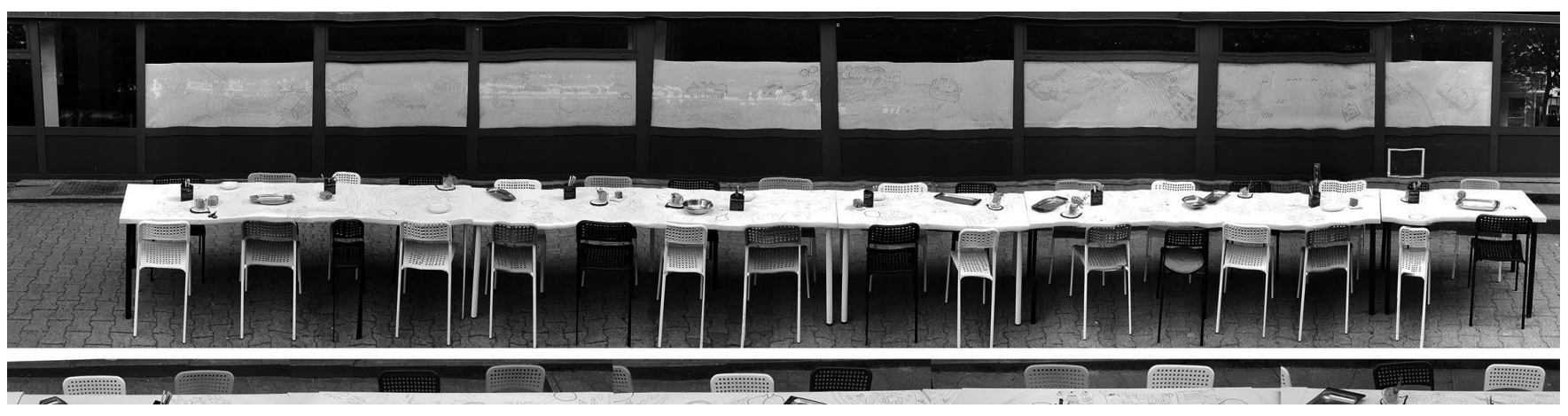

Figure 1: Drawing Table event set-up: storefront and table as drawing sites (photos: A Steinmuller)

to the line drawing base, thus producing a multivalent, multicentered, multi-authored, and 'multi-storied' composition of urban space. Co-producing a fairly utopian representation of the city, the project succeeded in the co-existence of the architects' and public's vision, until it didn't. Late in process, overriding graffiti-type markings overwhelmed the earlier work. As a criteria for drawing as community tool, curation and continued engagement become key points to maintain some control of the design act and enhance community/ architect dialogue.

As seen in the body of work by urbanist/artist Candy Chang, simple designs, well-positioned in public, can reveal the unseen community and their unheard voices. In projects such as the Before I Die... series [2011- ], a public surface is inscribed with a prompt for individual citizen participation. In this case, a vacant wall becomes a community chalkboard, populated with a grid of lines prompting 'Before I Die. " and room for response. The prompts act as a format for collective communication and reveal the identities and stories of a community. These become transformations of public communication typologies into sites of collective dialogue. Merging the graphic broadcasting and scale of urban billboards with the kiosk's invitation for interaction, these transformed communication typologies become forms and forums for public expression.

As part of their urban practice, Atelier Bow-Wow explores collective representations of the city and representations of the collective city. This quasi-anthropological trajectory of their work explores the behavior of the public in public, as documented by the spatial configurations within urban contexts. In drawings like Temple of Heaven (from Urban Forest) [2015], architect-designed artifacts, people, and ad-hoc spatial configurations, ones people construct themselves with furniture and props or with their groupings, are rendered with graphic equivalence and architectural precision. In projects such as The Making of a Public Drawing [2011], they involve students in the construction of large, field-like representations of public space. Their multiple eyes and hands lead to rich and multivalent understandings of the spatial configurations and behaviors of the public. In work by Manuel Bailo Esteve, such as Public Catalyst (Water Hydrant) [2017], representations of the everyday are separated graphically by color. A colored open hydrant and flowing water are in dialogue with the monochrome playing children documenting the social/spatial catalysts in public space and their use. In both, the recognitions of the catalytic potential for everyday space-definition provides the architect a body of evidence for the capacity of the productive use and misuse by citizens' own temporary design of space. Productive limits for the architect interested in harnessing understandings of these spatial configurations and behaviors of the public in public are summed up by Atelier Bow-Wow when they state, the "practice of architectural design in accordance with the theory of commonality [...] must adopt an abductive role." ${ }^{10}$

\section{DRAWING TABLE, BERLIN: A CO-DRAWING EXPERIMENT}

Leveraging a combination of these methods, the authors conducted a co-drawing experiment with students from California College of the Arts (CCA) during an advanced elective travel studio in Berlin, Germany. Since the fall of the wall, Berlin has developed of unique culture of citizen engagement. Initially sparked by the surplus of vacant land in transition of ownership in East Berlin, spontaneous appropriation of urban space by creatives and entrepreneurial citizens became common place. The city became a defacto "laboratory for the business of temporary use." ${ }^{11}$ Many of the impromptu occupations stimulated long-term development by changing public image of the location in question, and by pioneering new use concepts that established long-term transformations of a site, or were multiplied and redeployed in alternative locations across the city ${ }^{12}$. The impact of the temporary interventions of the 1990s echoes to this day in the proactive attitude of Berlin citizens towards spatial opportunities in an increasingly gentrified city. Most recently, this has manifested itself in the citizen-initiated process around the future use of Haus der Statistik ${ }^{13}$, as a site for artist workspaces and refugee housing, and in a larger trend of close citizen involvement in redevelopment projects.

On one such redevelopment project, the authors and their students collaborated with Raumlaborberlin, an experimental architecture practice renowned for its collaborative approach to transforming urban space. Raumlabor had recently 

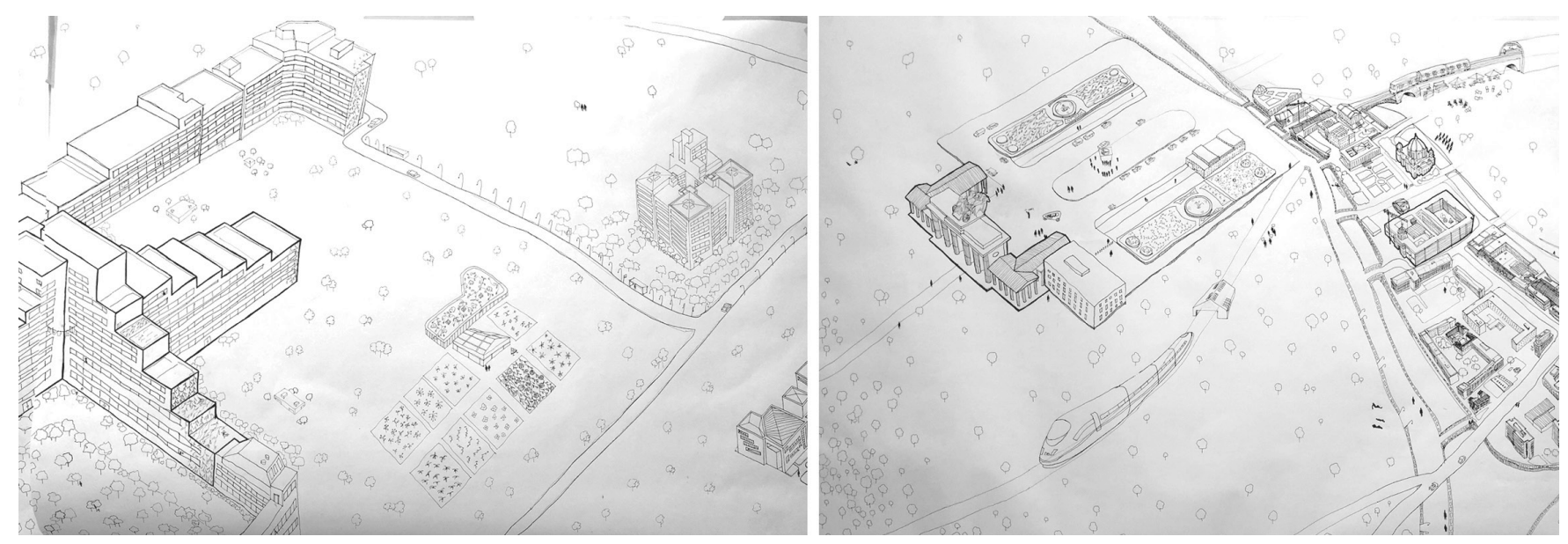

Figure 2: Excerpts from the incomplete base-drawing of Hafenplatz and its extended neighborhood (photos: A. Steinmuller)

become involved in the redevelopment of Hafenplatz, a large building complex from the 1970s. Initially designed as student housing, the complex has turned into poorly maintained social housing. It now houses a highly diverse population with many recent immigrants living there. A group of developers recently acquired Hafenplatz, envisioning a vibrant urban quarter, maintaining parts of the building and its housing use, and establishing various new, needed programs. While this project appears as to follow a conventional, investorinitiated process, the new owners intend to actively engage local residents and members of the public in decision-making. The project described in this paper - the result of a 3-week intensive studio course - constitutes an early step in this engagement, testing co-drawing as the catalyzing instrument for collaborative long-term and in-depth conversations about the future of the site.

To initiate this dialogue, the CCA team designed a public event, titled Drawing Table (or Zeichentisch), that offered two drawings as sites for capturing citizen input. The event took place outside of a former supermarket in the building complex. Its storefront was used as the location of one of the drawings. In the highly trafficked open space in front of the supermarket, a $30^{\prime}$ long table served as the location for the second drawing, for eating dinner, and for conversation (figure 1). The event was advertised through posters, flyers, and a large sign nearby. The team identified three sites for leveraging architectural expertise. In the following paragraphs, these sites are described as 'frameworks' that structure conversation, method of engagement, and spatial interface.

\section{FRAMEWORK 1: STRUCTURING CONVERSATION}

How does one use a drawing event to spark a productive, targeted conversation? The beginning of a planning process can be delicate in that it might be faced with adversarial reactions despite its goal for an inclusionary process of citizen engagement. To narrow the conversation, and to preclude a conversation focused on planning outcomes, the CCA team chose questions that could reveal sites of identity and community, focusing on the present condition of the site and neighborhood, and people's relationship to it. These questions were put forward in the form of 'menus', akin to Candy Chang's prompts, on the table that solicited drawings of personal, temporal, and communal focal points of the extended site around Hafenplatz.

\section{FRAMEWORK 2: DESIGNING INTERFACES}

Many conventional drawing methods are not intuitively understandable to the layperson. Considering the common legibility of models and aerials, the need to represent spatial adjacencies, and to include different scales in relationship to the Hafenplatz complex, its position in the neighborhood and the larger city, the team decided on a composite 'map' of axonometric/perspectival depictions building, neighborhood, and city. Beginning with the Hafenplatz complex and its immediate context on the left, a 30 ' long composite panorama extended into the immediate and extended neighborhood, incorporating at the far right some of the iconic sites of Berlin that they city might be known for by recent arrivals. The different locations were stitched together through fictitious pathways and adjacencies that could be associated with the city's public transportation systems. The result was a 30 ' long multi-centered, multi-scalar drawing - collectively produced by a team of students - whose built-in blank areas could hold multiple narratives and scales of association (figure 2). The base drawings were constructed with single line weights and simple, articulations of urban spaces.

The team produced two versions of this drawing-as-interface in order to test different forms of recording and organizing citizen input. Building on the table as a typology for social interaction and discussion, the second version of the drawing was conceived as a table cover, mounted as a continuous horizontal surface on a 30 ' long table. While the general order 

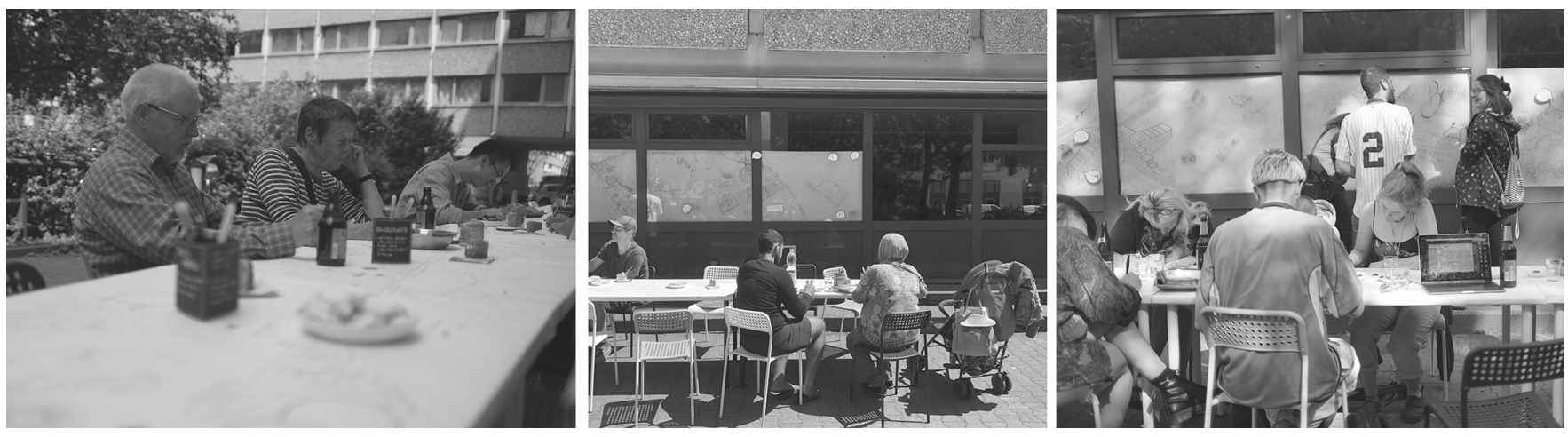

Figure 3: Different degrees of collaboration while engaging in drawing production (photos: Z.Wang (left, right); A.Steinmuller (center))

and content of the drawing was kept consistent, the table version of the drawing contained occasional plan projections in order to make visible interior spaces. The storefront version of the drawing was mounted inside the windows facing the table, aligned to parallel the drawing content on the table outside. Drawing on the typology of murals for telling stories back to a community, this drawing was visible from afar for passersby. In contrast to the drawing on the table, this base drawing offered the glass to serve as a working surface. This allowed a parallel experiment with the table drawing as active, and the storefront as an archival interface - one collapsing drawing framework and additions, and the other consciously separating and curating the two.

\section{FRAMEWORK 3: SHAPING ENGAGEMENT}

Conventional community engagement tend to take place in formal meetings, and are often involuntarily hierarchical with louder voices rising to the top. Community feedback is recorded through notes that may not capture everything that is being said. Co-drawing as a instrument for collective dialogue promises an alternative path of informal citizen engagement and direct recording of ideas in a non-hierarchical environment. In the Drawing Table, drawing event, food and drink, and an ad-hoc pingpong table created an informal, party-like atmosphere. The combination of elements helped to break down barriers to conversation. Members of the CCA team casually engaged in conversation with individuals, explaining the drawing and larger project. As people took a seat at the table, their input was gathered directly and individually through drawing. The length of the table allowed these drawn contributions to either take place in isolation, in one-on-one conversation with a team member, or as part of a group discussion (figure 3 ).

Not everyone feels comfortable when asked to draw. In order to accommodate varying comfort levels, the Drawing Table event offered a range of options for participation. An informal conversation with a team member provided the first step. Pens and markers invited citizens to draw directly on the table drawing. To prioritize approachability, the team leveraged familiar media forms from comic strips. Stacks of paper 'speech bubbles' (or 'drawing bubbles') were placed across the table to test and produce small scale drawings (figure 5, left). Team members also offered to draw for or with citizens, if someone was truly hesitant to contribute by drawing. Each 'drawing bubble' was then placed to the window surface in specific dialogue with the storefront drawing. In a final act of archiving and curation, team members translated the community's 'drawing bubbles' and table drawings on to the storefront glass (figure 4). The thickness of the glass in outdoor daylight conditions produced a light shadow for each line on the glass, emphasizing the collection of citizen drawings in relationship to the base-drawing.

\section{CO-DRAWING: THE EVENT AND ITS RESULTS}

In an attempt to capture a snapshot of the complex daily life of the neighborhood, the Drawing Table event lasted 12 hours, covering the lunch hour, kids after-school time, people returning from work, dinner, and those venturing out at night to meet friends. The drawings, the long table, and eventually the gathering of people themselves, sparked curiosity. People of all ages and demographic were happy to engage in the drawing experiment.

The team's engagement as moderators proved to be crucial. Initial one-on-one conversations with citizens about their concepts of identity, home, and community in relation to Hafenplatz often turned into deeper conversations, which revealed quite spatial, oral histories. In one example, someone described how music defines home and community for him, but could not imagine how to add this in drawing form. Further questions revealed that music, for him, related to ballroom dancing, and then the particular space in the extended neighborhood that served as a community hub for this. Rather than drawing sheet music (his initial idea), his addition to the drawing highlighted this ballroom dancing venue. 

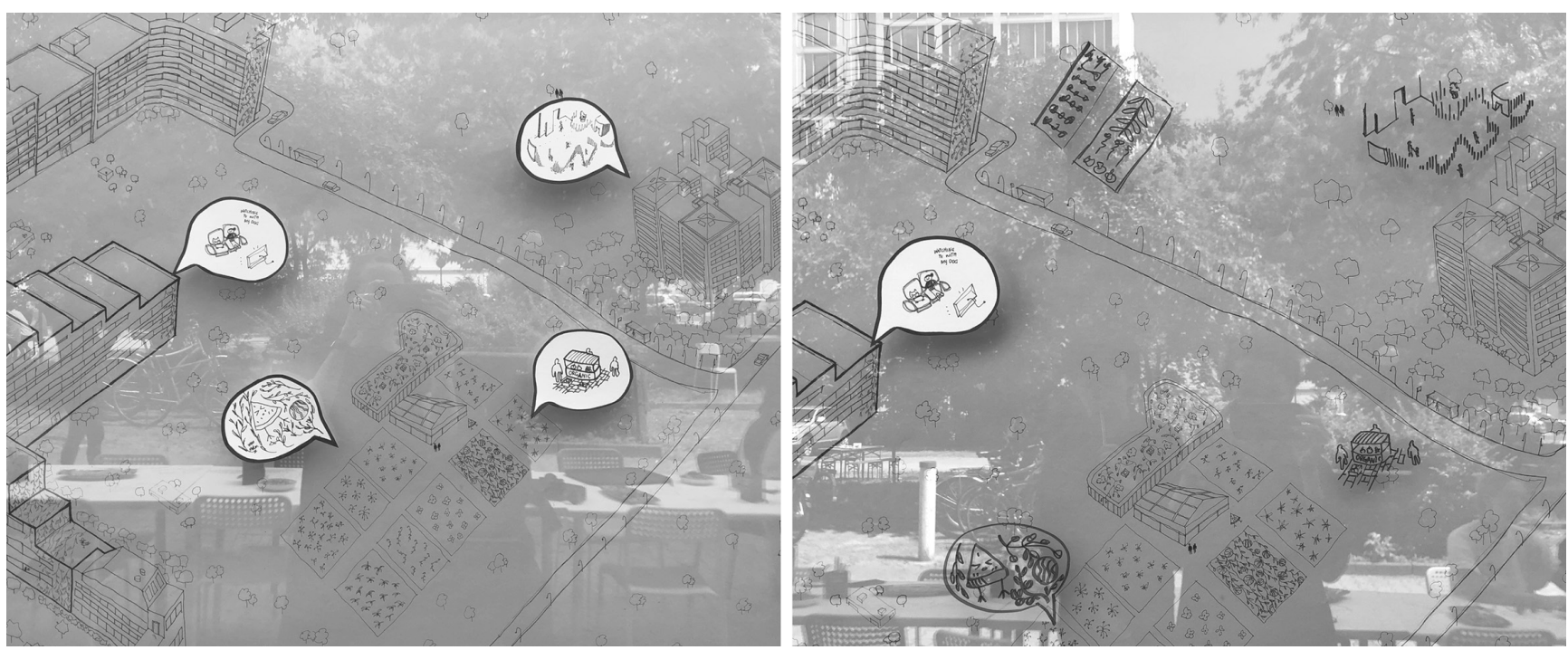

Figure 4: 'Drawing bubbles' mounted on storefront glass (left); translation into drawings on the glass (right) (photos: A. Steinmuller)

The final act of curation and translation also proved critical. As team members drew the content of the 'drawing bubbles' directly onto the glass in the locations chosen by each citizen, drawings became more clear. Drawing them in a similar hand with more expertise gave the composite a more unified language, clarifying content and concentrations over individual expression. In the final hours of the event, moderation and curation began to wane. Some people drew directly onto the glass when no one was looking. The table drawings began to include graffiti, and food spillage added to the texture of the table surface as the informal party atmosphere took over (Figure 5, right). The experience made clear the need for a focused and structured event in order for co-drawing to be a successful instrument.

\section{CONCLUSION}

Co-drawing can be seen as a design tool, and as part of a process to co-produce public space. It is a framework for both absorbing public contribution, and for setting forward further action and consensus. The co-drawing, therein, is both interface (multi-centered) and process (multi-authored), leveraging design expertise towards frameworks for collective dialogue. This expertise is manifest in shaping the conversation through formulating specific questions and scope; in designing an incomplete base drawing as interface for citizen interaction; and in shaping engagement through the defining methods of producing, curating, and archiving input through drawing.

As a result of the Berlin Drawing Table experiment, it was clear that the format of a travel studio was not an ideal scenario. While potentially catalytic to the process at Hafenplatz, akin to Archigram's 'Event' stage, the CCA event did not include an no opportunity to follow up on lessons learned and assess longer-term effect. The design of the questions needs rigor and iteration similar to architectural programming exercises, and the studio questions may not have been ideal. They proved too abstract for some people, and not spatial enough to yield enough productive results. The co-drawing process would need to be tested with questions that are more forward-pointing. More prior analysis of the community, or more dialogue with them, would have assisted in constructing more pertinent dialogues. The choice of drawing content is also crucial to solicit a response people would be invested in. The base drawing content needs continual experimentation to balance documentation of existing sites with speculative prompts. This would increase the potential for the drawing to assess real potentials and problems, and to stimulate ideas without prescribing finished outcomes.

From the experiences during the Drawing Table event, it was clear that helping a community envision their own urban or common space requires architectural expertise. As seen in the precedents and the Berlin experiment, the co-drawing format is both the construction of a $2 \mathrm{D}$ representational space and composition and the spatial design of a temporary community engagement event. Designing the process means also designing the form, space, and event that constructs community dialogue. The architect's expertise is thus limited in the amount that is controlled, but is expanded to spatialize aspects of the process to better serve and empower a community. It continues historical trajectories leveraging the potential for urban representation as stimulants for dialogues about the city's formation. 

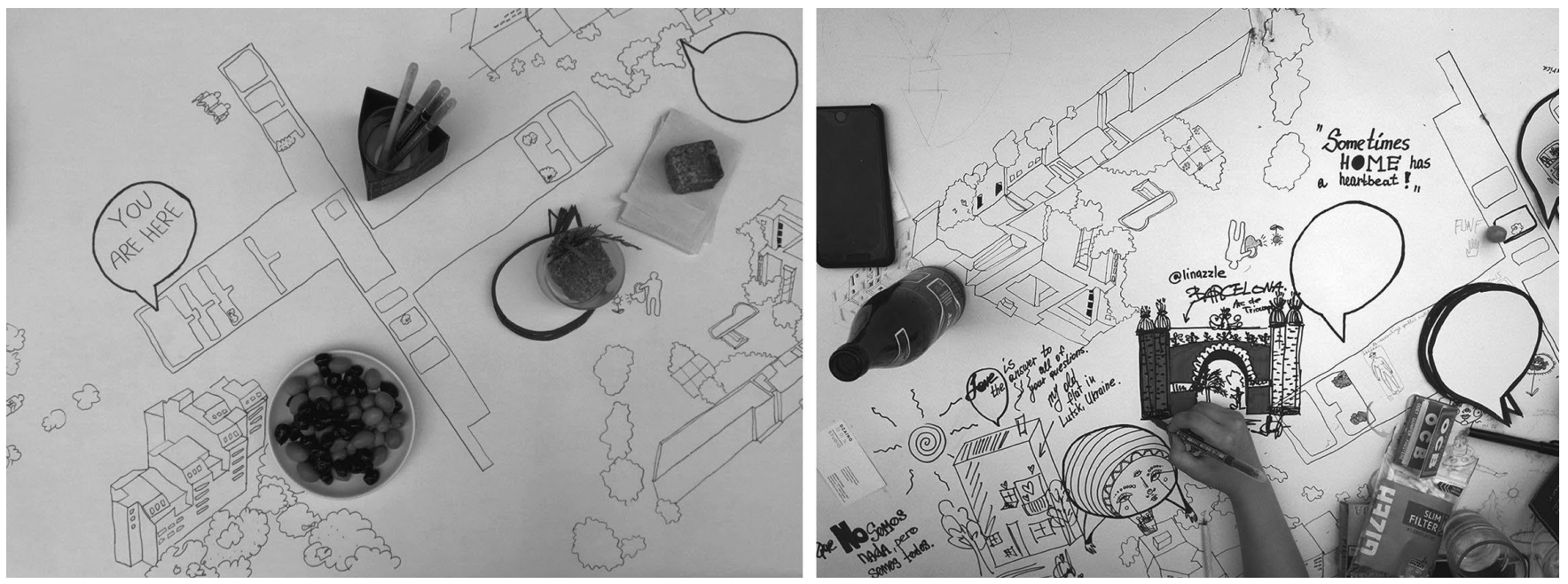

Figure 5: Initial table drawing set-up with 'drawing bubbles' (left, photo: A Steinmuller); late-night 'grafiti' (right, photo: Z.Wang)

\section{ENDNOTES}

1. Jeffrey Hou, ed., Insurgent Public Space: Guerrilla Urbanism and the Remaking of Contemporary Cities, (London: Routledge, 2010),7.

2. Jean Baudrillard, The Ecstasy of Communication (Cambridge: Semiotext(e) / Foreign Agents, 1988).

3. Jeremy Till, "The Negotiation of Hope," in Architecture and Participation, ed. Peter Blundell Jones et al. (New York: Taylor \& Francis, 2005), 30.

4. Barbara A. Kaminska, “'Come, let us make a city and a tower:" Pieter Bruegel the Elder's Tower of Babel and the Creation of a Harmonious Community in Antwerp," Journal of Historians of Netherlandish Art 6:2, Summer 2014

5. Hans Belting, Hieronymus Bosch: Garden of Earthly Delights (New York: Prestel; Reprint edition, 2016.), 7.

6. Jimenez Lai, The Politics of Flatness (Chicago: Treatise Publication Series, 2015), 10.

7. Lai, Politics, 10.

8. John McMorrough, "The Architecture of No Place and Eutopia, Infinite Earths and Elsewheres," in Citizen of No Place: An Architectural Graphic Novel. By Jimenez Lai (Princeton: Princeton Architectural Press, 2012), 9.

9. Atelier Bow-Wow, Urban Forest (Berlin: Haus der Kulturen der Welt and Spector Books, 2015), 106. Daniel M. Abramson, Obsolescence : An Architectural History. Daniel M. Abramson (Chicago ; London : The University of Chicago Press, 2016), 53.

10. Ingeborg Junge-Reyer, "Preface," in Urban Pioneers, ed. StudioUC/Klaus Overmeyer (Berlin: Jovis, 2007), 17.

11. Philipp Oswalt, Klaus Overmeyer, Philipp Misselwitz, Urban Catalyst (Berlin: DOM Publishers, 2013), 61. 